\title{
LA FASCINACIÓN POR EL PAISAJE: UNA VISTA DEL GRAN CAÑÓN DEL PINTOR JOSÉ ARPA PEREA
}

\section{THE FASCINATION FOR THE LANDSCAPE: A VIEW OF THE GRAND CANYON BY THE PAINTER JOSÉ ARPA PEREA}

\author{
Carmen Rodríguez Serrano \\ Grupo de Investigación HUM-210: Laboratorio de Arte \\ rodriguezserranocarmen@gmail.com
}

\begin{abstract}
El presente texto pone de manifiesto la fascinación que sintió el pintor José Arpa Perea por el paisaje americano y concretamente por las vistas del Gran Cañón de Arizona a través de un interesante ejemplo.

Palabras clave: José Arpa Perea; pintura andaluza; siglo XX; Gran Cañón; Arizona.

This paper reveals the fascination felt by the painter José Arpa Perea for the American landscape and for the views of the Grand Canyon in Arizona through an interesting example.

Keywords: José Arpa Perea; Andalusian painting; $20^{\text {th }}$ century; Grand Canyon; Arizona.
\end{abstract}

Si hay algo que caracteriza la obra de José Arpa Perea es su interés hacia el paisaje. Desde muy temprano en su pintura predominaron vistas fluviales y de la naturaleza, encontrando también entre ellas accidentes geográficos. En un primer momento, las representaciones paisajísticas que se observan en su producción aluden a su tierra, Andalucía, unas visiones que retomará en los años finales de su vida, tras haber conocido y captado las singularidades de lugares tan sorprendentes como los que le ofrecieron México o Estados Unidos. En este último contexto se enmarca la pintura a la que se dedica estas líneas, una obra perteneciente al conjunto de vistas del Gran Cañón de Arizona que José Arpa realizó hacia 1925 y en las que se advierte la gran capacidad pictórica del artista a la hora de trabajar la luz, la composición y el color. Dicha creación presenta un encuadre particular que la relaciona con otras obras entre su producción y que, sin duda, 
aporta interés al lienzo. No obstante, el hecho de que esta obra se encontrara en paradero desconocido hasta este presente año ha motivado e incentivado su estudio y revisión.

Como se ha señalado, José Arpa es un pintor eminentemente paisajista. Las diferentes investigaciones, estudios ${ }^{1}$ y exposiciones ${ }^{2}$ realizadas en torno a su obra así lo han demostrado. Tras su regreso de Roma, donde disfrutó de una estancia formativa entre 1883 y 1886, se vinculó con los jóvenes pintores de la Escuela de Alcalá, los cuales practicaban un paisaje realista con base luminista al plein air que tomó como principal fuente de inspiración la ribera del río Guadaíra y la del propio Guadalquivir. En esta línea y entre los primeros años de la década de 1890 va a realizar una serie de interesantes paisajes y vistas fluviales en los que la pincelada se va volviendo cada vez más movida y pastosa. En 1897, motivado por diferentes circunstancias, entre ellas la de la búsqueda de nuevas tierras y luces que capturar, marchó al continente americano. Los paisajes de México en un primer momento y, más tarde, los de Estados Unidos ${ }^{4}$ se presentaron ante los ojos de Arpa como mundos repletos de posibilidades cromáticas y lumínicas. A este último país llega en 1910, aunque no será hasta 1923 cuando fije su residencia en San Antonio, ciudad en la que dos años más tarde abrió su propia escuela de arte. Lo cierto es que pese a establecerse en un lugar, Arpa tuvo un carácter viajero que le impulsó a realizar excursiones con sus alumnos no solo en los alrededores del mismo, sino también en estados cercanos como Arizona, Nuevo México, etc.

Vista del Gran Cañón ${ }^{5}$ pertenece al conjunto o serie que el pintor realizó hacia 1925 de este imponente monumento natural que tanto debió impresionar a

${ }^{1}$ Este artículo se extrae de las investigaciones realizadas para la ejecución de la tesis doctoral por RODRÍGUEZ SERRANO, Carmen: El pintor José Arpa Perea y la renovación de la pintura sevillana de su tiempo. Sevilla, 2015. Dicha tesis tiene presencia en diversas publicaciones, tales como RODRÍGUEZ SERRANO, Carmen: "Colores y luces de los Estados Unidos de América: una visión del exitoso pintor viajero José Arpa a través de la prensa", Laboratorio de Arte, 28, 2016, pp. 543-564; y RODRÍGUEZ SERRANO, Carmen: José Arpa Perea, un pintor viajero. Visiones de México, Texas y Sevilla (1858-1952). Sevilla, 2017.

${ }^{2}$ Catálogo de la exposición José Arpa Perea. Sevilla, 1998.

${ }^{3}$ Una de las primeras investigaciones sobre José Arpa en México fue la de GALÍ BOADELLA, Montserrat: "José Arpa Perea en México (1895-1910)", Laboratorio de Arte, 13, Sevilla, 2000, pp. 241-261.

${ }^{4}$ En Estados Unidos, la figura del pintor fue estudiada dentro de algunas publicaciones, tales como BATTAILE FISK, Frances: A History of Texas Artists and Sculptors. Austin, 1986; FORRESTER-O'BRIEN, Esse: Art and Artists of Texas. Dallas, 1935; o STEINFELDT, Cecilia: Art for History's Sake. The Texas Collection of the Witte Museum. San Antonio, 1993.

5 Óleo sobre lienzo de 61 x 50,8 cm, firmado y titulado en el ángulo inferior izquierdo: Jose Arpal Grand Canyon Ariz. 
Arpa en su visita a Arizona. La pintura, que se encontraba en paradero desconocido, tal y como se recoge en el catálogo de la exposición sobre el autor celebrada en Sevilla en $1998^{6}$, y en el que no se aporta más información, pertenece a una colección privada texana ${ }^{7}$ y apareció en el mes de mayo de 2017 en subasta a través de Heritage Auctions, America's Auction House, con el número de lote 75038. Su valor estimado oscilaba entre los 40.000 y los 60.000 dólares americanos. No obstante, esta obra fue "apartada" de la subasta por una serie de cuestiones relacionadas con sus propietarios. Junto a ella aparecieron otras tres pinturas de idéntica autoría, a las que al igual que la comentada se les había perdido la pista en el año 1944 y que, asimismo, fueron retiradas. Esta circunstancia inicial supuso el estudio a color de la pieza, en su máximo esplendor, pudiéndose apreciar la riqueza cromática propia de la obra de Arpa.

Al observar la pintura, en primer término y en el lado izquierdo del espectador, el artista sitúa un avance rocoso con alguna vegetación dispersa que enmarca la propia vista del Cañón. Este aparece en un segundo plano, en su completa majestuosidad, extendiéndose en el horizonte e incluso perdiéndose en el mismo. Esta circunstancia hace que el espacio reservado al celaje sea casi mínimo.

El formato de la obra es especial puesto que la mayoría de las versiones conocidas del Gran Cañón presentan una disposición horizontal. En este caso, al igual que sucede con la pintura conservada en el Panhandle-Plains Historical Museum de Canyon, Texas, el formato es vertical y el espacio dispuesto para el cielo es casi inexistente. Ello se ve determinado por el encuadre captado por Arpa, muy cercano al carácter fotográfico propio de la pintura impresionista. Este recurso de apariencia casual, instantánea, es una singularidad de la obra del pintor. Es frecuente encontrar en su producción encuadres complejos como el que se analiza. Pinturas como el Tajo de Ronda, el Nacimiento del Mississippi o su Vista del puerto de Rota vienen a redundar en esta idea. En la última obra señalada, de nuevo se observa el recurso de disponer en primer término un avance rocoso repleto, en este caso, de vegetación, que enmarca la escena principal del puerto en segundo término. Con esta disposición el pintor busca crear una táctica efectista con la que captar la atención de aquel que contemple la obra.

El artista, como ya se ha señalado, era conocido por las diversas excursiones que realizaba para captar de primera mano y al plein air paisajes tan diversos como el de una cantera, un campo de flores o el de un río. En todos ellos el estudio de la luz era la clave, una luz que plasmada sobre el lienzo, en ocasiones, parecía irreal. Esta circunstancia es la que acompaña a la serie de vistas del Cañón y concretamente a la que se analiza, donde el empleo de las tonalidades moradas, naranjas, azules, amarillas, colores que predominan sobre la línea, completamente

\footnotetext{
${ }^{6}$ Catálogo de la exposición José Arpa Perea, op. cit., p. 172.

${ }^{7}$ Se trata de una colección privada, cuyos propietarios prefieren mantener el anonimato.
} 
desdibujada, generan en el espectador un desconcierto inicial. Arpa pinta lo que sus ojos ven. El efecto de la luz a diferentes horas del día modifica considerablemente una superficie. La plasmación de un amanecer, un atardecer o la impresión del mediodía implica el uso de una paleta variada y sorprendente. Las propias circunstancias telúricas del Gran Cañón hacen que el estudio de la luz a diferentes horas del día provoque unas escenas casi de ensueño, irreales. Ante los ojos del espectador se presentan tonalidades aparentemente ilusorias, pero que son asombrosamente reales. Eso es lo que el pintor representó.

La pintura pudo ser realizada durante las primeras horas del día, puesto que la luz, aunque incide sobre el Cañón, no es cegadora. Resulta llamativo, en este sentido, observar cómo el espacio próximo al pintor está más definido y los colores son aparentemente más verosímiles que los que se disponen en el horizonte de la garganta del río Colorado.

Pero esta, tal y como ya se adelantó, no es la única versión que del Gran Cañón realizó. Entre las diferentes vistas que ejecutó Arpa se conocen unas diez versiones, aunque es probable que existan algunas más. El hecho de que la mayoría de la obra del pintor se encuentre en colecciones privadas entre España, México y Estados Unidos imposibilita conocer en profundidad su número exacto. De entre ellas, al menos tres se encuentran en Sevilla, siendo de gran calidad la del Museo de Bellas Artes y la que es propiedad de la Real Academia de Bellas Artes de Santa Isabel de Hungría.

El estudio de Vista del Gran Cañón pone de manifiesto lo prolífico de la obra de Arpa y la gran calidad pictórica que desarrolló a lo largo de su trayectoria artística. Los paisajes estadounidenses que inmortalizó, del mismo modo que lo hace su naturaleza, muestran la grandiosidad y belleza del país en su totalidad. Como ya se señaló, no cabe duda de que debió de pintar numerosas versiones del tema, que, como esta, se espera que sigan apareciendo, para engrosar su magnífico catálogo.

Fecha de recepción: 30 de octubre de 2017

Fecha de aceptación: 12 de abril de 2018 


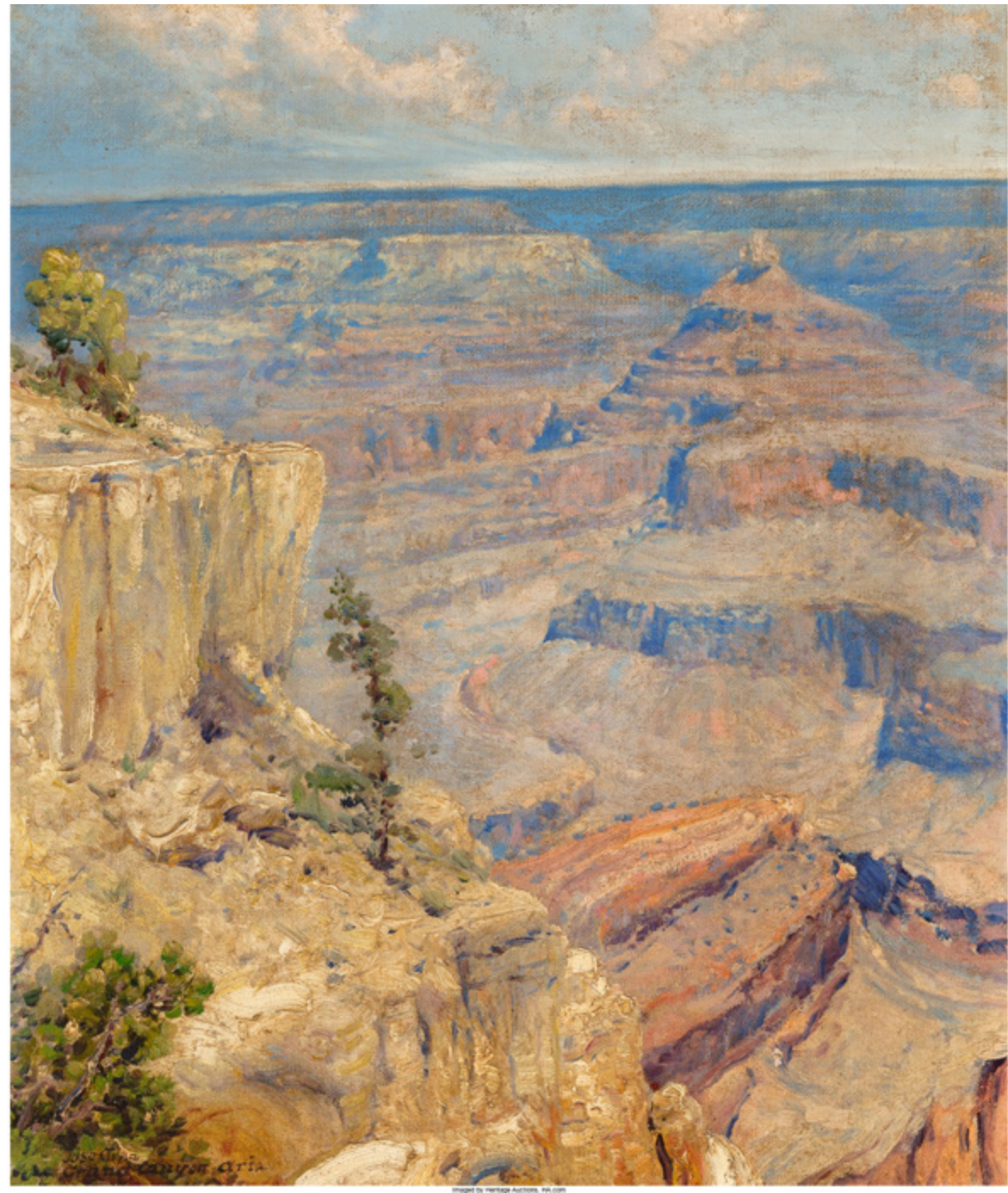

Figura 1. José Arpa Perea, Vista del Gran Cañón, hacia 1925, colección privada. 


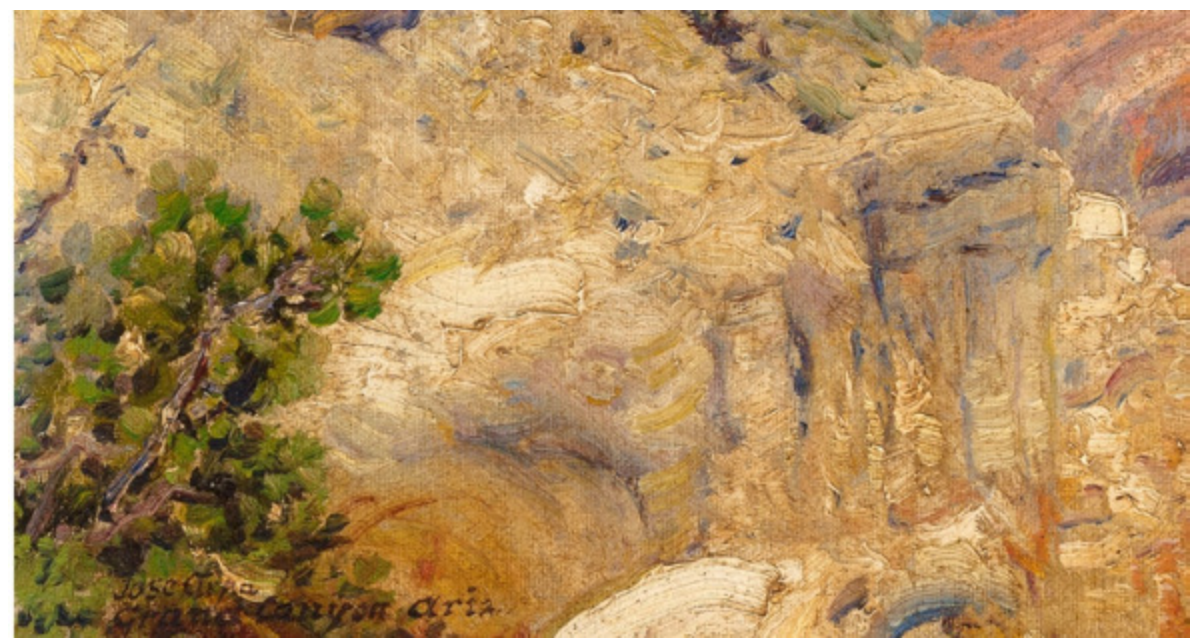

Figura 2. José Arpa Perea, Vista del Gran Cañón (detalle de la firma), hacia 1925, colección privada. 